
April 1940

\title{
NOTE ON THE EFFECT OF PRESSURE ON THE WAVE- LENGTHS OF THE INTERNATIONAL SECONDARY STANDARDS IN THE FIRST SPECTRUM OF IRON
}

\author{
By Curtis J. Humphreys
}

ABSTRACT

The wavelengths of the lines in the first spectrum of iron, adopted as secondary standards by the International Astronomical Union in 1928 and 1938, have been compared with the wavelengths of the same set of lines, observed by Burns and Walters using a vacuum-arc source. The International Standard wavelengths are derived from observations with the specified Pfund arc operated in air. Consequently the two sets of data permit a check on the pressure effect in Fe I. Term depressions obtained by this comparison agree reasonably well with those observed by Babcock.

The widespread use of the lines of the spectra of iron as standards of wavelength makes it important that the dependence of wavelengths upon operating conditions to which the source is subjected be determined. The Pfund arc, as specified by the International Astronomical Union [1], ${ }^{1}$ is used as the source of the secondary standards in the iron spectra. The essential feature of the specification, that the radiation used be taken from the central zone of a relatively long arc, is intended to eliminate pole effect. The spectrum from this source is, however, subject to the displacement arising from the pressure of the atmosphere. The so-called vacuum arc, because of the relatively low operating pressure, exhibits a negligible pressure effect and the pole effect has not been detected in it.

Earlier investigations of the pressure effect, particularly in the spectra of iron, have been discussed by the author in a recent paper on the pressure effect in Fe II [2]. Reference is made here only to the work of Gale and Adams [3], and of Babcock [4]. Gale and Adams separated the observed lines into four groups, designated by the letters $a, b, c$, and $d$, according to the amount of pressure displacement. A fifth group, designated $e$, consisting of lines showing a negative pressure effect, that is a diminution of wavelength with increased pressure on

1 Figures in brackets indicate the literature references at the end of this paper. 
the source, was noted by St. John and Ware [5]. Group $e$ is not considered in this study because it contains no secondary standards. It was shown by Babcock that this grouping could be explained on the basis of the term classifications of the lines, assuming that the effect of pressure manifests itself in a lowering of the spectral terms, being relatively greater for the higher terms. The results of Gale and Adams were considerably larger than Babcock's, a feature explained by the latter on the basis of the presence of both pole effect and pressure effect in the radiation. Babcock operated his source in air in accordance with the IAU specification for the production of standards free from pole effect. No further measurements of pressure displacements in $\mathrm{Fe}$ I have been reported during the past 11 years.

Additional information regarding the pressure effect in Fe I may be obtained from a study of available interference measurements. The International secondary standards [6] represent the mean of three or more concordant comparisons of the wavelengths from the Pfund arc with the primary standard or an equivalent group of noble-gas lines. Burns and Walters [7] have made interference measurements of the wavelengths of the lines of $\mathrm{Fe}$ I from the vacuum arc in like manner. Wavelengths of lines common to these two sets of data should show a systematic difference attributable to pressure effect.

It is the purpose of this note to report and discuss the depressions of the levels of Fer, resulting from a pressure difference of 1 atmosphere, corresponding to the respective operating conditions of the Pfund arc, specified as the source of International secondary standard wavelengths, and the vacuum arc, used by Burns and Walters.

For purposes of this study, the lines were grouped according to multiplets. Burns and Walters give wave numbers computed from average terms in addition to the observed values for most lines. Both have been compared with the wave numbers appropriate to the International secondary standards. The computed wave numbers are dependent on the observations of several different lines and may therefore be regarded as somewhat more accurate than the individual observed wave numbers. Such computed wave numbers might also be expected to give a somewhat more regular set of pressure displacements when subtracted from the wave numbers belonging to the International lines. This expectation, however, was not uniformly supported by the results. Consequently, both sets of differences were given equal weight in deriving depressions of the terms resulting from pressure.

The calculation of the depressions of the terms of a spectrum from the pressure displacements of individual lines has been discussed by Babcock [4] and by the author [2]. These depressions are all relative to the lowest state, assumed to have zero depression, and can be computed to the extent permitted by the availibility of lines involving transitions between levels, one of which has a known depression. The results of this study are given in table 1 . 
TABLE 1.-Term depressions in Fe I

\begin{tabular}{|c|c|c|c|c|c|c|c|c|c|}
\hline \multicolumn{2}{|c|}{ Term } & \multirow{2}{*}{$\begin{array}{l}\text { Num- } \\
\text { ber of } \\
\text { com- } \\
\text { bina- } \\
\text { tions }\end{array}$} & \multicolumn{2}{|c|}{$\begin{array}{l}\text { D epression } \\
\text { resulting from } \\
1 \text { atmosphere } \\
\text { press u r e } \\
\text { change }\end{array}$} & \multicolumn{2}{|c|}{ Term } & \multirow{2}{*}{$\begin{array}{l}\text { Num- } \\
\text { ber of } \\
\text { com- } \\
\text { bina- } \\
\text { tions }\end{array}$} & \multicolumn{2}{|c|}{$\begin{array}{l}\text { Depression } \\
\text { resulting from } \\
1 \text { atmcsptere } \\
\text { pres s u r } \\
\text { change }\end{array}$} \\
\hline $\begin{array}{l}\text { Designa- } \\
\text { nation }\end{array}$ & $\begin{array}{l}\text { Mag- } \\
\text { nitude }\end{array}$ & & $\begin{array}{c}\text { This } \\
\text { analysis }\end{array}$ & $\begin{array}{l}\text { Bab- } \\
\text { cock }\end{array}$ & $\begin{array}{l}\text { Designa- } \\
\text { tion }\end{array}$ & $\underset{\text { nitude }}{\text { Mag- }}$ & & $\begin{array}{c}\text { This } \\
\text { analysis }\end{array}$ & $\begin{array}{l}\text { Bab- } \\
\text { cock }\end{array}$ \\
\hline & $\mathrm{cm}^{-1}$ & & $\mathrm{~cm}^{-1}$ & $\mathrm{~cm}^{-1}$ & & & & & \\
\hline$a^{5} \mathrm{D}$ & & & 0.000 & 0.000 & $x^{3} \mathrm{D}^{\circ}$ & 45,300 & 7 & .022 & \\
\hline$a^{5} \mathrm{~F}$ & 7,500 & & 0.000 & 0.000 & $y^{3} \mathrm{G}^{\circ}$ & 45,400 & 4 & .020 & \\
\hline$a^{3} \mathrm{~F}$ & 12,500 & & .000 & .001 & $x^{5} \mathrm{G}^{\circ}$ & 45,800 & 2 & 015 & \\
\hline$a^{5} \mathrm{P}$ & 17,700 & & 003 & .003 & $16^{\circ}$ & 46,720 & 2 & 025 & \\
\hline$a^{3} \mathrm{P}$ & 18,700 & & .004 & .002 & $17^{\circ}$ & 46,745 & 1 & 030 & \\
\hline$a^{3} \mathrm{H}$ & 19,600 & & 004 & .003 & $18^{\circ}$ & 46,888 & 2 & 030 & \\
\hline$z^{7} \mathrm{D}^{\circ}$ & 19,600 & 2 & .004 & .003 & $19^{\circ}$ & 46,889 & 1 & 022 & \\
\hline$b^{3} \mathrm{~F}$ & 20,800 & & .005 & 003 & $y^{3} \mathrm{P}^{\circ}$ & 46,900 & 3 & 028 & \\
\hline$a^{3} \mathrm{G}$ & 22,000 & & 006 & .007 & $z^{3} \mathrm{H}^{0}$ & 47,000 & 2 & 027 & \\
\hline$b^{2} \mathrm{P}$ & 22,900 & & 007 & & $w^{3} \mathrm{D}^{\circ}$ & 47,100 & 5 & 030 & \\
\hline$z^{7} \mathrm{~F}^{\circ}$ & 23,000 & 3 & .008 & .006 & $21^{\circ}$ & 47,177 & 1 & 030 & \\
\hline$b^{3} \mathrm{G}$ & 24,100 & & .008 & & $23^{\circ}$ & 47,419 & 1 & 037 & \\
\hline$z^{7} \mathrm{P}^{\circ}$ & 24,100 & 1 & .010 & .005 & $z^{3} \mathrm{~S}^{\circ}$ & 47,500 & 1 & 046 & \\
\hline 1 & 24,335 & & .008 & & $b^{5} \mathrm{~F}$ & 47,700 & 2 & 037 & .033 \\
\hline 2 & 24,574 & & .008 & & $25^{\circ}$ & 47,834 & 2 & 039 & \\
\hline 3 & 24,772 & & .008 & & $26^{\circ}$ & 47,966 & 1 & 012 & \\
\hline$z^{5} \mathrm{D}^{\circ}$ & 26,200 & 21 & .009 & 008 & $28^{\circ}$ & 48,1 & 1 & 012 & \\
\hline$z^{5} \mathrm{~F}^{\circ}$ & 27,300 & 17 & 008 & 009 & $30^{\circ}$ & 48,238 & 4 & 014 & \\
\hline$z^{5} \mathrm{P}^{\circ}$ & 29,400 & 5 & 014 & 012 & $31^{\circ}$ & 48,289 & 1 & 022 & \\
\hline$z^{3} \mathrm{D}^{\circ}$ & 31,600 & 6 & 006 & .006 & $32^{\circ}$ & 48,304 & 3 & 025 & \\
\hline$z^{3} \mathrm{~F}^{\circ}$ & 31,700 & 6 & .015 & .008 & $36^{\circ}$ & 48,702 & 1 & 021 & \\
\hline$y^{5} \mathrm{D}^{\circ}$ & 33,600 & 16 & 018 & 015 & $37^{\circ}$ & 49,108 & 1 & 006 & \\
\hline$y^{5} \bar{F}^{\circ}$ & 34,200 & 20 & .010 & .013 & $40^{\circ}$ & 403 & 1 & 016 & \\
\hline$z^{3} \mathrm{P}^{\circ}$ & 34,200 & 5 & .010 & .013 & $44^{\circ}$ & 49,604 & 2 & 017 & \\
\hline$z^{5} \mathrm{G}^{\circ}$ & 35,400 & 16 & .009 & .011 & $45^{\circ}$ & 49,627 & 1 & 021 & \\
\hline$z^{3} \mathrm{G}^{\circ}$ & 35,700 & 13 & .019 & 014 & 50 & 50,3 & 1 & 023 & \\
\hline$y^{3} \mathrm{~F}^{\circ}$ & 37,100 & 13 & .019 & 01 & 51 & 50,3 & 2 & 028 & \\
\hline$y^{5} \mathrm{P}^{\circ}$ & 37,100 & 6 & .015 & .007 & 52 & 50,4 & 3 & 034 & \\
\hline$y^{3} \mathrm{D}^{\circ}$ & 38,600 & 8 & .017 & 015 & 55 & 50,534 & 2 & 038 & \\
\hline$x^{5} \mathrm{D}^{0}$ & 40,000 & 14 & .019 & .020 & 60 & 50,8 & 1 & 033 & \\
\hline$x^{\circ} \mathrm{F}^{\circ}$ & 40,700 & 3 & 017 & & 61 & 50,833 & 2 & 028 & \\
\hline$z^{5} \mathrm{~S}^{\circ}$ & 40,900 & 3 & .017 & .010 & 67 & 50,998 & 1 & 019 & \\
\hline$y^{5} \mathrm{G}^{0}$ & 43,000 & 7 & -.008 & & 70,71 & 51,148 & 1 & 042 & \\
\hline$a^{7} \mathrm{D}$ & 43,400 & 5 & .036 & .027 & 72 & 51,192 & 1 & 002 & \\
\hline$w^{5} \mathrm{D}^{\circ}$ & 44,000 & 3 & .011 & & 73 & 51,208 & 1 & 014 & \\
\hline $7^{\circ}$ & 44,243 & 1 & .014 & & 75 & 51,228 & 1 & 032 & \\
\hline $9^{\circ}$ & 44,415 & 1 & .041 & & $a^{3} \mathrm{D}$ & 51,700 & 1 & 041 & 035 \\
\hline $11^{\circ}$ & 44,551 & 1 & .000 & & $c^{5} \mathrm{D}$ & 52,000 & 1 & 036 & .029 \\
\hline$b{ }^{5} \mathrm{D}$ & 45,300 & 4 & .031 & .029 & & & & & \\
\hline
\end{tabular}

The designations of the terms, or numbers assigned to unclassified levels, appearing in the first column are in the notation used by Bacher and Goudsmit [8]. Column 2 gives the relative term magnitudes starting with the ground state zero, as is customary in discussions of this spectrum. Entries rounded off to hundreds represent the average positions of the groups of multiple levels constituting known terms. This procedure follows Babcock's example in setting up the corresponding table. In column 3 the number of combinations with lower levels is indicated. Inasmuch as all lines were given equal weight, these numbers give an indication of the weight to be associated with the pressure displacement found for any term. No entries are shown 
opposite the low and intermediate even terms. Displacements corresponding to these terms had to be adopted in a somewhat different manner, as explained below, so that the number of combinations of the low even terms with high odd terms does not have the same significance as that of the numbers entered. The fourth column contains the term depressions obtained by this comparison of the International standards with the Burns-Walters data; and finally, in the last column are the corresponding term depressions obtained by Babcock from his own observations.

While it is apparent that, in general, the term depression increases with elevation of the term, it is doubtful if the effect has been measured precisely enough to establish a definite functional relationship. The low $a^{5} \mathrm{~F}$ term appears to have no displacement relative to the ground state $a^{5} \mathrm{D}$, as shown by lines involving combinations with higher common odd levels. On the same basis the moderately low $a^{3} \mathrm{~F}$ and $a^{5} \mathrm{P}$ do not show a displacement relative to $a^{5} \mathrm{D}$. The low odd septets are only slightly higher than $a^{5} \mathrm{P}$, and exhibit a measurable pressure displacement, which is apparent in the relatively intense intersystem combinations with the ground state. Even levels of the same magnitude are expected to show about the same pressure displacements. This would lead to the expectation that the even levels between 19,000 and $24,000 \mathrm{~cm}^{-1}$ would be displaced relative to the low terms. Combinations with high odd terms indicate that these levels have about the same displacement as $a^{5} \mathrm{P}$ but about $0.007 \mathrm{~cm}^{-1}$ greater on the average than $a^{3} \mathrm{~F}$. Inasmuch as other evidence shows $a^{3} \mathrm{~F}$ and $a^{5} \mathrm{P}$ to be affected about the same by pressure, it is seen that the results are somewhat contradictory. The values assigned to the even levels between 17,500 and 24,000 appear to be the best possible compromise, but are to a certain extent arbitrary.

The term depressions which can be compared with Babcock's show reasonably satisfactory agreement, so that his conclusions regarding the relationship between pressure displacement and term magnitude are supported by most of the results here presented. No clear-cut evidence for a systematic difference between the displacements of triplets and terms of higher multiplicities is shown. There is, therefore, no separate listing in the table. Babcock's observations were limited to the wavelength interval 3895 to $6677 \mathrm{~A}$. The International standards, including those adopted at the most recent meeting of the IAU [6], cover the interval 2447 to $6677 \mathrm{~A}$.

The pressure displacements obtained from data in the interval between 2447 and 3895 A frequently come out unexpectedly small and occasionally exhibit negative values. Inclusion in this paper of data from the region of wavelengths shorter than $3895 \mathrm{~A}$ has the effect of making many of the observed term depressions smaller than expected on the basis of earlier estimates. Whether there is any theoretical significance to be attached to this fact, it is impossible to say at present. However, attention should be called to the diminishing precision of observations as one goes toward the ultraviolet. Two reasons for this may be mentioned. The first is inherent in the Fabry-Perot interferometer and arises from a falling off of the reflecting power of metal films with diminishing wavelengths, resulting in poorer definition of interference fringes. The second reason is that the ratio $d \lambda / d \mu$ decreases toward the ultraviolet. In a determination 
of term depressions, one is at a disadvantage because line displacements are measured, whereas it is a change in wave number which is required.

Because of the need of improved standards in the ultraviolet region and of the desirability of obtaining better agreement with the pressure displacements observed in the visible region, it is apparent that additional precise observations could be profitably undertaken.

\section{REFERENCES}

[1] Trans. Int. Astron. Union 2, 36 (1925).

[2] Curtis J. Humphreys, J. Research NBS 23, 125 (1939).

[3] Henry G. Gale and Walter S. Adams, Astrophys. J. 35, 10 (1912).

[4] Harold D. Babcock, Astrophys. J. 6\%, 240 (1928).

[5] Charles E. St. John and L. W. Ware, Astrophys. J. 39, 5 (1914).

[6] Trans. Int. Astron. Union 3, 77 (1928); 6, 85 (1938).

[7] K. Burns and F. M. Walters, Jr., Pub. Allegheny Observatory Univ. Pittsburgh 6, 159 (1929); 8, 39 (1931).

[8] Robert F. Bacher and Samuel Goudsmit, Atomic Energy States (McGrawHill, New York, N. Y., 1932).

WASHINGTON, January 12, 1940. 